\title{
Long-term Transanal Excision Outcomes in Patients With T1 Rectal Cancer: Comparative Analysis of Radical Resection
}

\author{
Yunghuyn Hwang, Yong Sik Yoon, Jun Woo Bong, Hye Yun Choi, In Ho Song, Jong Lyul Lee, \\ Chan Wook Kim, In Ja Park, Seok-Byung Lim, Chang Sik Yu, Jin Cheon Kim \\ Division of Colon and Rectal Surgery, Department of Surgery, Asan Medical Center, University of Ulsan College of Medicine, Seoul, Korea
}

Purpose: Transanal excision (TAE) is an alternative surgical procedure for early rectal cancer. This study compared longterm TAE outcomes, in terms of survival and local recurrence (LR), with total mesorectal excision (TME) in patients with pathologically confirmed $\mathrm{T} 1$ rectal cancer.

Methods: T1 rectal adenocarcinoma patients who underwent surgery from 1990 to 2011 were retrospectively reviewed. Patients that were suspected to have preoperative lymph node metastasis were excluded. Demographics, recurrence, and survival were analyzed based on TAE and TME surgery.

Results: Of 268 individuals, 61 patients $(26 \%)$ underwent TAE, which was characterized by proximity to the anus, submucosal invasion depth, and lesion infiltration, compared with TME patients $(\mathrm{P}<0.001-0.033)$. During a median follow-up of 10.4 years, 12 patients had systemic and/or LR. Ten-year cancer-specific survival in the TAE and TME groups was not significantly different $(98 \%$ vs. $100 \%)$. However, the 10 -year LR rate in the TAE group was greater than that of TME group ( $10 \%$ vs. $0 \%, \mathrm{P}<0.001)$. Although 5 of the 6 TAE patients with LR underwent salvage surgery, one of the patients eventually died. The TAE surgical procedure (hazard ratio, 19.066; $\mathrm{P}=0.007$ ) was the only independent risk factor for LR. Conclusion: Although long-term survival after TAE was comparable to that after TME, TAE had a greater recurrence risk than TME. Thus, TAE should only be considered as an alternative surgical option for early rectal cancer in selected patients.

Keywords: Rectal neoplasms; Colorectal surgery; Survival

\section{INTRODUCTION}

Colorectal cancer is the third most common malignancy in South Korea, and its annual associated age-standardized cancer mortality and incidence rates are increasing [1]. The current standard of surgery for mid- to low-rectal cancer is total mesorectal excision (TME) with radical resection of the rectum. TME in rectal cancer has led to dramatic improvements in the local recurrence (LR)

Received: August 30, 2018 - Accepted: October 18, 2018

Correspondence to: Yong Sik Yoon, M.D.

Division of Colon and Rectal Surgery, Department of Surgery, Asan Medical

Center, University of Ulsan College of Medicine, 88 Olympic-ro 43-gil,

Songpa-gu, Seoul 05505, Korea

Tel: +82-2-3010-5318, Fax: +82-2-474-9027,Email: yoonys@amc.seoul.kr ORCID code: https://orcid.org/0000-0002-3196-8423

(C) 2019 The Korean Society of Coloproctology

This is an open-access article distributed under the terms of the Creative Commons Attribution NonCommercial License (http://creativecommons.org/licenses/by-nc/4.0) which permits unrestricted noncommercial use, distribution, and reproduction in any medium, provided the original work is properly cited. rate and anal sphincter preservation [2]. However, TME has some disadvantages that are associated with radical resection, including longer surgical times and higher morbidity and mortality, and it also is associated with a greater risk of loss of anorectal function [3].

Transanal excision (TAE) is a procedure that involves local excision for benign and malignant rectal neoplasms. TAE can be performed to identify pathology or for local control of benign and early rectal malignancy without the risk of lymph node metastasis. Because there is a $10 \%-15 \%$ risk of lymph node metastasis for T1 rectal cancer, TAE should be considered only for selected patients that do not have a risk of lymph node metastasis, regardless of anorectal function [4].

In the present study, we reviewed patients with pathologically confirmed T1 rectal cancer who underwent TAE and TME and compared the long-term outcomes of the 2 groups in terms of survival and recurrence. 


\section{METHODS}

\section{Patients}

Data from pT1 rectal adenocarcinoma patients who underwent surgery from January 1990 to December 2011 were retrospectively reviewed. The data included age, sex, lesion size, distance from the anal verge, serum carcinoembryonic antigen (CEA) level, histology type and grade, lymphovascular invasion, depth of invasion, and adjuvant therapy. Exclusion criteria were: (1) preoperative suspicion of lymph node metastasis, (2) age greater than 79 years or less than 19 years, (3) upper rectal cancer, i.e., a lower tumor border located $10 \mathrm{~cm}$ or more proximally from the anal verge, (4) noncurative surgery (R1 or R2), (5) preoperative chemoradiation, (6) pathology other than adenocarcinoma, (7) recurrent or metastatic cancer, (8) unclear pathologic data, including depth of tumor or lymphovascular invasion, and (9) less than 6 months of follow-up. This study was approved and was exempted from informed consent by the Institutional Review Board of the Asan Medical Center (approval number: 2018-1135).

\section{Transanal excision}

The indications and detailed procedures for TAE in our institution were described in our previous study [5]. Indications for TAE include a small (less than $3 \mathrm{~cm}$ ), movable, palpable with index finger and well to moderately differentiated tumor. The tumor should be at the T1 stage without invading more than $30 \%$ of the rectal circumference and without lymph node metastasis on preoperative transrectal ultrasonography, computerized tomography, or magnetic resonance imaging.

Patients had $4 \mathrm{~L}$ of polyethylene glycol orally on the day before surgery and fasted from midnight. Surgery was performed under either general or spinal anesthesia. A urinary catheter was inserted after the anesthesia, and the patient's position was changed to a prone jack-knife position. After dilation and adequate traction of the anal canal, the tumor was identified and excised under direct vision at full thickness with margins of at least $0.5 \mathrm{~cm}$. The rectal wall defect was repaired with absorbable sutures. A single surgical instrument used for transendoscopic microsurgery has not been identified at our institution. Cases of transanal minimally invasive surgery were not included due to the heterogeneity of the procedure and scarcity of cases.

\section{Definitions}

Patients were placed into a TAE or a TME group, depending on the procedure. Five patients that underwent TAE followed by TME because of adverse histologic findings were included in the TME group. Distance from anal verge was dichotomized at under or over $5 \mathrm{~cm}$ from the anal verge, which divides the low rectum from the mid rectum [6]. Tumor size was dichotomized at $\geq 3 \mathrm{~cm}$ or $<3 \mathrm{~cm}$ [7]. The threshold for elevated serum CEA was $6 \mathrm{ng} /$ $\mathrm{mL}$, which is the normal limit at our institution. The depth of invasion into the submucosa was classed as sm1 (upper third), sm2 (middle third), and sm3 (lower third) for sessile tumors $(\mathrm{n}=254)$ [8]. Pedunculated lesions $(n=14)$ were categorized by Haggitt level [9]. Haggitt levels 3-4 and sm2-3 were grouped as deep submucosal invasions $[4,10]$. The favorable histology group had well-differentiated or moderately differentiated adenocarcinomas, whereas the unfavorable histology group contained poorly differentiated or mucinous adenocarcinomas $[5,11]$. The risk factors for lymph node metastasis were: defined tumors with any type of deep submucosal invasion, lymphovascular invasion, and unfavorable histology. Recurrence included LR, systemic recurrence, and both recurrences concomitantly.

\section{Follow-up}

Patients received standardized postoperative follow-up, including clinical examinations, complete blood counts, blood chemistry tests, serum CEA quantitation, and chest radiography, every 6 months for the first 2 years postoperatively and every 12 months thereafter. They also underwent abdominal and pelvic computed tomography (CT) scanning and transrectal ultrasound (TUS) every 12 months. Colonofiberoscopy or sigmoidofiberoscopy was performed every 6 months after the first postoperative year and then annually thereafter. Patients with suspected recurrence had individualized examinations including specific imaging work-up (e.g., TUS, CT, magnetic resonance imaging, and/or positron emission tomography) or biopsy. Survival status and date of death were confirmed by follow-up data.

\section{Adjuvant therapy}

Adjuvant chemoradiation therapy was considered in cases within the TME group with lymph node metastasis and within the TAE group that exhibited sm2 or sm3, lymphovascular invasion, unfavorable histologic findings, or close resection margins. Radiation therapy was delivered by a linear accelerator (Clinac 1800 instrument; Varian Medical Systems, Palo Alto, CA, USA). Patients were instructed to lie in a prone position, and 6 to $15 \mathrm{MV}$ of radiation was applied through 3 or 4 fields to the pelvis. Patients were irradiated with 2 Gy, 5 days a week, for a total dose of 50 Gy. The superior border for irradiation was the bottom edge of the fifth lumbar vertebra, and the inferior border was $3 \mathrm{~cm}$ caudal to the tumor. The lateral borders were 1.5 to $2.0 \mathrm{~cm}$ medial from the inner bony margin of the most lateral portion of the true pelvis. The anterior border was $3 \mathrm{~cm}$ ventral to the tumor, and the posterior border was $1 \mathrm{~cm}$ from the dorsal margin of the sacrum. The primary tumor, regional lymph nodes, and perirectal fat tissue were included in the target volume [5].

\section{Analysis \\ Data were reported as mean \pm standard deviation for continuous variables and as frequency (\%) for categorical variables. Univari- ate analyses were conducted to compare patient characteristics of the TAE and TME groups. Pearson chi-square test or Fisher exact test were used for categorical data, and the Student t-test was used}


for continuous data. The LR, recurrence-free survival (RFS), overall survival (OS), and cancer-specific survival (CSS) rates were calculated using the Kaplan-Meier method, and the log-rank test was used to compare differences among survival curves in univariate analyses. The potential prognostic factors that were screened in univariate analysis were further analyzed by multivariate analysis using a Cox regression model, and hazard ratios (HRs) were calculated with $95 \%$ confidence intervals (CIs). A Pvalue of $<0.05$ was considered statistically significant for all analyses, and all calculations were carried out using IBM SPSS Statistics ver. 24.0 (IBM Co., Armonk, NY, USA).

\section{RESULTS}

\section{Patient characteristics}

Of the 268 pathologic T1 rectal cancer patients, 61 (22.8\%) underwent TAE and 207 (77.2\%) underwent TME. The TAE group was characterized by tumors that were closer to the anus $(\mathrm{P}<$ $0.001)$, more frequent deep submucosal invasion lesions ( $\mathrm{P}=$ $0.02)$, and more frequently infiltration $(\mathrm{P}=0.033)$. Thirty-two patients $(52.5 \%)$ in the TAE group had risk factors for lymph node metastasis, which was less frequent than for the TME group $(\mathrm{P}=$ $0.013)$ (Table 1). There were no differences between the groups in age, sex ratio, tumor size, lymphovascular invasion, tumor differentiation, and serum CEA level.

\section{Survival and recurrence}

The follow-up period had a median of 10.4 years (range, 1.6-20.6 years), and the 10-year OS rate for TAE patients was not different from the TME group (91\% vs. 90\%) (Table 2). The 10-year CSS rate for TAE was slightly lower than for the TME group ( $98 \%$ vs. $100 \%)$, although this result was not statistically significant ( $\mathrm{P}=$ 0.22) (Fig. 1). There was no difference in the 10 -year OS and CSS rates for lymph node metastasis risk factors (Table 2).

Table 2. Long-term oncologic outcomes

\begin{tabular}{|c|c|c|c|c|c|}
\hline \multirow{2}{*}{ Outcome } & \multicolumn{2}{|c|}{5 Years } & \multicolumn{2}{|c|}{10 Years } & \multirow{2}{*}{ P-value } \\
\hline & TAE & TME & TAE & TME & \\
\hline Overall survival (\%) & 95 & 97 & 91 & 90 & 0.910 \\
\hline Without risk factor & 97 & 100 & 96 & 94 & 0.680 \\
\hline With risk factor & 94 & 96 & 90 & 88 & 0.890 \\
\hline Cancer-specific survival (\%) & 98 & 100 & 98 & 100 & 0.220 \\
\hline Without risk factor & 100 & 100 & 100 & 100 & 0.220 \\
\hline With risk factor & 97 & 99 & 97 & 99 & 0.320 \\
\hline Recurrence-free survival (\%) & 90 & 99 & 86 & 99 & $<0.001$ \\
\hline Without risk factor & 96 & 100 & 93 & 100 & 0.038 \\
\hline With risk factor & 84 & 98 & 80 & 97 & 0.001 \\
\hline Local recurrence rate (\%) & 10 & 0 & 10 & 0 & $<0.001$ \\
\hline Without risk factor & 4 & 0 & 4 & 0 & 0.140 \\
\hline With risk factor & 16 & 1 & 16 & 1 & $<0.001$ \\
\hline
\end{tabular}

TAE, transanal excision; TME, total mesorectal excision.

Risk factors included deep submucosal invasion, lymphovascular invasion, and poor histology results.

Table 1. Clinicopathologic characteristics

\begin{tabular}{|c|c|c|c|c|}
\hline Variable & Total $(n=268)$ & $\operatorname{TAE}(n=61)$ & TME $(n=207)$ & P-value \\
\hline Age (yr) & $58.8 \pm 9.6$ & $58.0 \pm 9.5$ & $59.0 \pm 9.6$ & 0.290 \\
\hline Female sex & $117(43.7)$ & $28(45.9)$ & $89(43.0)$ & 0.770 \\
\hline Distance from anal verge $(\mathrm{cm})$ & $6.2 \pm 2.6$ & $4.1 \pm 2.0$ & $6.8 \pm 2.4$ & $<0.001$ \\
\hline Tumor size $\geq 3 \mathrm{~cm}$ & $54(22.5)$ & $8(15.7)$ & $46(24.3)$ & 0.260 \\
\hline Lymph node metastasis & & & $15(7.3)$ & \\
\hline Deep submucosal invasion & $174(64.9)$ & $32(52.5)$ & $142(68.6)$ & 0.020 \\
\hline Lymphovascular invasion & $30(11.2)$ & $4(6.6)$ & $26(12.6)$ & 0.250 \\
\hline Unfavorable histology & $4(1.5)$ & $2(3.3)$ & $2(1.0)$ & 0.224 \\
\hline Elevated CEA & $5(1.9)$ & $3(5.1)$ & $2(1.0)$ & 0.078 \\
\hline Growth type & & & & 0.033 \\
\hline Expanding & $194(78.9)$ & $45(90.0)$ & $149(76.0)$ & \\
\hline Infiltrative & $52(21.1)$ & $5(9.6)$ & $47(24.0)$ & \\
\hline With risk factor & $176(42.9)$ & $32(52.5)$ & $144(69.6)$ & 0.013 \\
\hline Chemotherapy & $48(17.9)$ & $10(16.4)$ & $38(18.4)$ & 0.850 \\
\hline Radiation therapy & $28(10.4)$ & $18(29.5)$ & $10(4.8)$ & $<0.001$ \\
\hline
\end{tabular}

Values are presented as mean \pm standard deviation or number (\%).

TAE, transanal excision; TME, total mesorectal excision; CEA, carcinoembryonic antigen.

Deep submucosal invasion included sm2-3 for sessile tumor and Haggitt level 3-4 for pedunculated tumor. 
Twelve patients had systemic and/or LR, which are described in Table 3. In total, $75 \%$ of recurrence cases $(n=9)$ developed within 5 years postoperatively. The 10-year RFS rate for TAE was lower than that for TME ( $86 \%$ vs. $99 \%, \mathrm{P}<0.001)$. A TAE surgical procedure was the only independent risk factor for recurrence (HR, 6.8; 95\% CI, 2.0-22.5; P = 0.002) (Table 4).

The 10-year LR rate for TAE was greater than for TME (10\% vs. $0 \%, \mathrm{P}<0.001$ ) (Fig. 2). Among patients with risk factor for lymph node metastasis, the 10 -year LR rate for TAE was $16 \%$ compared to $1 \%$ of TME $(\mathrm{P}<0.001)$ (Table 2$)$. Of the 5 TAE patients with LR, four had salvage surgery but one of the patients eventually died. The patient that did not undergo salvage surgery was lost to follow-up immediately after confirmation of recurrence. The me-

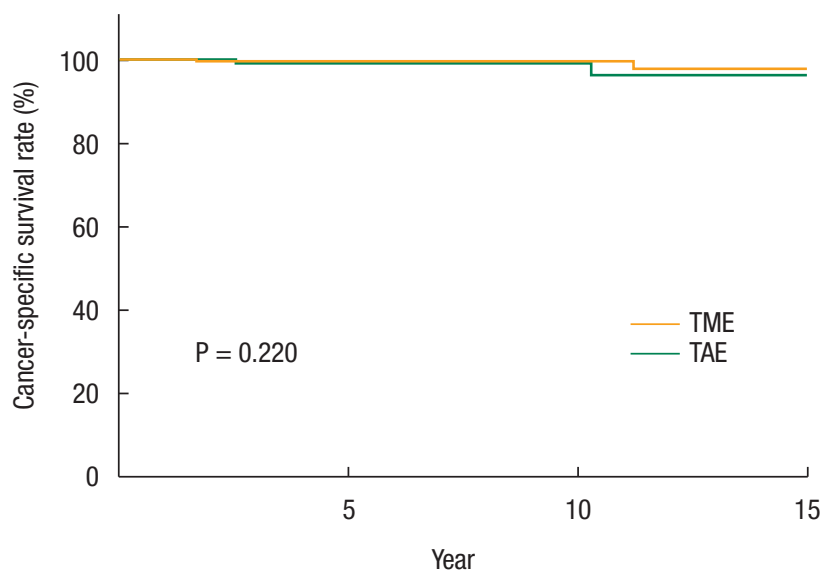

Fig. 1. Kaplan-Meier survival curves of cancer-specific survival rate based on surgery type. TME, total mesorectal excision; TAE, transanal excision. dian time from initial surgery to salvage surgery was 18 months, and the mean survival after LR was 12 years. The TAE surgical procedure (HR, 19.1; 95\% CI, 2.3-159.8; $\mathrm{P}=0.007)$ was the only independent risk factor for LR (Table 5).

\section{DISCUSSION}

For the past two decades, TAE has been used as a potential alternative to TME in patients with early rectal cancer. Although there have been many reports on TAE, few studies have been conducted in South Korea [7, 12]. The present study is significant because of a long-term follow-up of more than 10 years and the relatively large number of patients from a single tertiary referral cen-

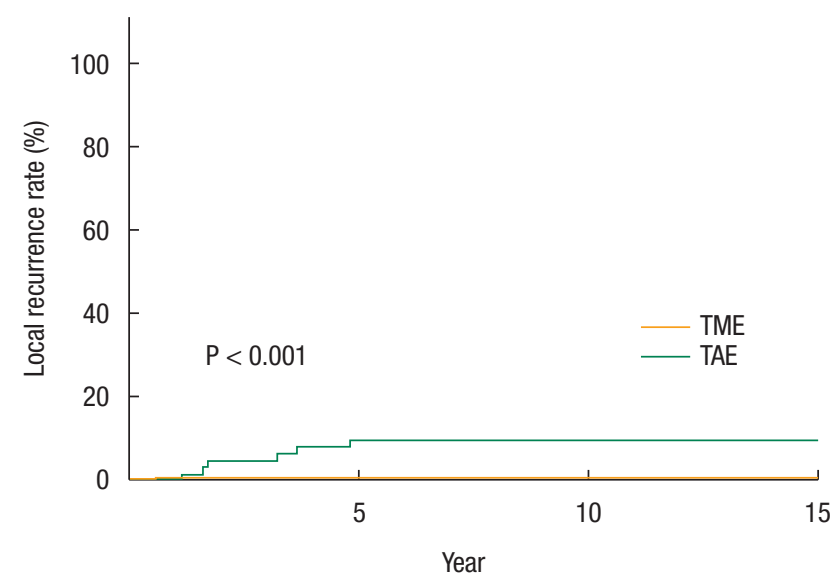

Fig. 2. Kaplan-Meier survival curves of local recurrence rate based on surgery type. TME, total mesorectal excision; TAE, transanal excision.

Table 3. Recurrence patterns and treatment approaches

\begin{tabular}{|c|c|c|c|c|c|c|c|c|}
\hline Sex & Age & Recurrence type & Operation & Salvage surgery & Last status & $\begin{array}{c}\text { Recurrence- } \\
\text { free survival (mo) }\end{array}$ & $\begin{array}{l}\text { Survival after } \\
\text { recurrence }(\mathrm{mo})\end{array}$ & $\begin{array}{l}\text { Adjuvant therapy } \\
\text { after recurrence }\end{array}$ \\
\hline $\mathrm{F}$ & 35 & $L R$ & TAE & Yes & Alive & 44 & 46 & CTx $+R T x$ \\
\hline $\mathrm{F}$ & 48 & $\mathrm{LR}$ & TAE & No & Alive & 58 & 0 & No \\
\hline$F$ & 62 & $L R$ & TAE & Yes & Alive & 14 & 161 & No \\
\hline $\mathrm{F}$ & 46 & SR & TAE & Yes & Dead & 86 & 38 & CTx \\
\hline $\mathrm{F}$ & 59 & $L R+S R$ & TAE & No & Dead & 21 & 10 & CTx \\
\hline$M$ & 49 & $\mathrm{LR}$ & TME & Yes & Alive & 8 & 109 & $\mathrm{CTX}+\mathrm{RT} \mathrm{x}$ \\
\hline M & 63 & SR & TME & No & Dead & 84 & 51 & No \\
\hline
\end{tabular}

LR, local recurrence; SR, systemic recurrence; TAE, transanal excision; TME, total mesorectal excision; CTx, chemotherapy; RTx, radiation therapy. 
Table 4. Univariate and multivariate analyses of recurrence

\begin{tabular}{|c|c|c|c|c|c|c|}
\hline \multirow{2}{*}{ Variable } & \multicolumn{3}{|c|}{ Univariate analysis } & \multicolumn{3}{|c|}{ Multivariate analysis } \\
\hline & $\mathrm{HR}$ & $95 \% \mathrm{Cl}$ & P-value & $\mathrm{HR}$ & $95 \% \mathrm{Cl}$ & P-value \\
\hline \multicolumn{7}{|l|}{ Sex } \\
\hline Male & 1.000 & & & & & \\
\hline Female & 2.661 & 0.801-8.839 & 0.110 & & & \\
\hline \multicolumn{7}{|l|}{ Operation type } \\
\hline TME & 1.000 & & & 1.000 & & \\
\hline TAE & 6.759 & $2.035-22.453$ & 0.002 & 6.759 & $2.035-22.453$ & 0.002 \\
\hline \multicolumn{7}{|l|}{ Tumor size (cm) } \\
\hline$<3$ & 1.000 & & & & & \\
\hline$\geq 3$ & 0.841 & 0.179-3.965 & 0.830 & & & \\
\hline \multicolumn{7}{|l|}{ Distance from AV (cm) } \\
\hline$<5$ & 1.000 & & & & & \\
\hline$\geq 5$ & 0.386 & 0.116-1.282 & 0.560 & & & \\
\hline \multicolumn{7}{|l|}{ Depth of tumor } \\
\hline Shallow SM invasion & 1.000 & & & & & \\
\hline Deep SM invasion & 2.839 & $0.622-12.959$ & 0.180 & & & \\
\hline \multicolumn{7}{|l|}{ Histology } \\
\hline Favorable & 1.000 & & & & & \\
\hline Unfavorable & 7.183 & $0.923-55.881$ & 0.060 & & & \\
\hline \multicolumn{7}{|l|}{ Lymphovascular invasion } \\
\hline No & 1.000 & & & & & \\
\hline Yes & 1.701 & $0.373-7.765$ & 0.490 & & & \\
\hline \multicolumn{7}{|l|}{ CEA } \\
\hline Normal & 1.000 & & & & & \\
\hline Elevated & 4.914 & $0.634-38.084$ & 0.130 & & & \\
\hline \multicolumn{7}{|l|}{ Radiation therapy } \\
\hline No & 1.000 & & & & & \\
\hline Yes & 2.883 & $0.780-10.659$ & 0.110 & & & \\
\hline \multicolumn{7}{|l|}{ Chemotherapy } \\
\hline No & 1.000 & & & & & \\
\hline Yes & 0.945 & $0.207-4.312$ & 0.180 & & & \\
\hline
\end{tabular}

$\mathrm{HR}$, hazard ratio; Cl, confidence interval; TAE, transanal excision; TME, total mesorectal excision; AV, anal verge; SM, submucosal; CEA, carcinoembryonic antigen.

ter. Our major finding was that TAE results in a higher LR than TME, which was consistent with the results of previous studies [7, 13]. However, the elevated LR rate from TAE was not associated with poor long-term survival, compared with TME. These survival outcomes could be attributable to the relatively low incidence of LR in patients in this study, and the high frequency of salvage treatment upon LR.

The National Comprehensive Cancer Network guidelines are one of the most widely used recommendations in rectal cancer. Version 1.2018 for rectal cancer suggests criteria for TAE based on a study by Nash and colleagues $[7,14]$. The recommendations suggest that patients who have not experienced an endoscopically-removed polyp with cancer or indeterminate pathology can be candidates for TAE if the T1 tumors are under $3 \mathrm{~cm}$ and without lymph node metastasis, mobile, nonfixed and well- to moderately differentiated and within $8 \mathrm{~cm}$ of the anal verge with less than $30 \%$ of bowel invasion, and without lymphovascular invasion or perineural invasion. Full-thickness excision and a clear resection margin of over $3 \mathrm{~mm}$ should be confirmed. In the present study, most TAE patients fell within this guideline; however, some patients that did not meet these criteria were indicated for radical resection or adjuvant therapy. 
Table 5. Univariate and multivariate analyses of local recurrence

\begin{tabular}{|c|c|c|c|c|c|c|}
\hline \multirow{2}{*}{ Variables } & \multicolumn{3}{|c|}{ Univariate analysis } & \multicolumn{3}{|c|}{ Multivariate analysis } \\
\hline & HR & $95 \% \mathrm{Cl}$ & P-value & $\mathrm{HR}$ & $95 \% \mathrm{Cl}$ & P-value \\
\hline \multicolumn{7}{|l|}{ Sex } \\
\hline Female & 7.844 & $0.944-65.152$ & 0.060 & & & \\
\hline \multicolumn{7}{|l|}{ Operation type } \\
\hline TAE & 20.788 & $2.503-172.686$ & 0.005 & 19.066 & 2.274-159.832 & 0.007 \\
\hline \multicolumn{7}{|l|}{ Tumor size (cm) } \\
\hline$<3$ & 1.000 & & & & & \\
\hline$\geq 3$ & 0.033 & $0.000-118.142$ & 0.420 & & & \\
\hline \multicolumn{7}{|l|}{ Distance from AV (cm) } \\
\hline Shallow SM invasion & 1.000 & & & & & \\
\hline Deep SM inv. & 3.335 & $0.401-27.701$ & 0.650 & & & \\
\hline \multicolumn{7}{|l|}{ Histology } \\
\hline Favorable & 1.000 & & & 1.000 & & \\
\hline Unfavorable & 12.110 & $1.455-100.790$ & 0.021 & 6.846 & $0.808-57.976$ & 0.080 \\
\hline \multicolumn{7}{|l|}{ LVI } \\
\hline No & 1.000 & & & & & \\
\hline Yes & 1.370 & $0.165-11.382$ & 0.770 & & & \\
\hline \multicolumn{7}{|l|}{ CEA } \\
\hline \multicolumn{7}{|l|}{ Chemotherapy } \\
\hline No & 1.000 & & & & & \\
\hline Yes & 0.037 & $0.000-167.320$ & 0.440 & & & \\
\hline
\end{tabular}

HR, hazard ratio; Cl, confidence interval; TME, total mesorectal excision; TAE, transanal excision; AV, anal verge; SM, submucosal; LVI, lymphovascular invasion; CEA, carcinoembryonic antigen.

The 5-year LR rate in the TAE group (10\%) was not significantly different compared with the $7 \%$ to $17 \%$ reported in previous studies $[12,15,16]$. However, the TME group had an extremely low 5 -year LR rate $(0 \%)$, which was better than the results of other studies $(2 \%-6 \%)[12,13]$. In addition, the 5-year OS rates for TAE (95\%) and TME (97\%) in this study were better than those in previous reports ( $72 \%-89 \%$ for TAE and $80 \%-93 \%$ for TME) [13, $15,17]$. One possible explanation for these favorable outcomes is a lower frequency of unfavorable histology (1.5\%) compared with other studies $(5.3 \%-12.1 \%)[7,12]$. Another reason could be our exclusion of patients that were suspected to have lymph node metastasis. In addition, the effect of LR on long-term survival is still controversial. Some studies have shown a poorer survival after TAE because of high LR $[7,13,15]$. However, this study did not find a significant difference in OS as well as CSS, which is consistent with Bentrem et al. [17]. This trend could be attributed to the use of appropriate treatments, such as adjuvant chemoradiation therapy or salvage surgery.

Radiation therapy after local excision significantly improved 5 -year local control in high-risk patients with pT1 rectal cancer 
(89\% vs. 100\%) [18]. In another study of TAE in pT1 and pT2 patients, radiation therapy did not reduce overall recurrence but delayed LR (median 2.1 years with radiation vs. 1.1 years without radiation) [19]. A previous retrospective study of local excision at our institution revealed no difference in RFS rate based on radiation therapy [20]. Even if LR occurs after TAE, salvage surgery is a possibility for a significant number of cases and favorable OS outcomes are associated with appropriate salvage surgery. A previous investigation showed good outcomes in all six patients that received salvage surgery for LR, who were still alive at follow-up at 57 months [16]. In another study, 16 patients underwent salvage surgery, but 7 of the patients died [7]. Our four patients who had LR underwent salvage surgery and their 5 -year OS rate was $60 \%$, which was comparable to the $50 \%-58 \%$ reported in other studies $[17,21]$.

Lymphovascular invasion [12, 22], unfavorable histology [12], and depth of submucosal invasion [15] have been recognized as risk factors for recurrence after both TAE and TME. Although we could not identify any independent risk factors, other than the type of operation, these risk factors for lymph node metastasis were associated with a higher probability of LR for the TAE group in this study (HR, 5.797; 95\% CI, 1.1-31.7; P = 0.043). Therefore, patients with any risk factors should be considered for TME to optimize oncologic outcomes.

There were several limitations to this study. Because this was a single-center study, the results may not be externally validated and may differ to studies with different populations and in different settings [23]. Most importantly, since this was a retrospective study, the reasons for patients receiving TAE alone or in conjunction with radiation therapy or chemotherapy are unknown. A selection bias of procedure groups should also be considered because our TAE group had tumors with smaller sizes and that were closer to the anal verge. Therefore, it may have been more difficult to control for confounding variables and unmeasured parameters or misclassifications may have influenced survival [24].

In conclusion, TAE results in a greater risk of recurrence than TME, although long-term survival was comparable between the 2 procedures. Thus, TAE should only be considered for carefully selected patients as an alternative surgical option for early rectal cancer.

\section{CONFLICT OF INTEREST}

No potential conflict of interest relevant to this article was reported.

\section{REFERENCES}

1. Hur H, Oh CM, Won YJ, Oh JH, Kim NK. Characteristics and survival of Korean patients with colorectal cancer based on data from the Korea Central Cancer Registry Data. Ann Coloproctol 2018;34:212-21.
2. Heald RJ, Husband EM, Ryall RD. The mesorectum in rectal cancer surgery--the clue to pelvic recurrence? Br J Surg 1982;69:613-6.

3. Nastro P, Beral D, Hartley J, Monson JR. Local excision of rectal cancer: review of literature. Dig Surg 2005;22:6-15.

4. Choi PW, Yu CS, Jang SJ, Jung SH, Kim HC, Kim JC. Risk factors for lymph node metastasis in submucosal invasive colorectal cancer. World J Surg 2008;32:2089-94.

5. Im YC, Kim CW, Park S, Kim JC. Oncologic outcomes and proper surveillance after local excision of rectal cancer. J Korean Surg Soc 2013;84:94-100.

6. Park KK, Lee SH, Baek SU, Ahn BK. Laparoscopic resection for middle and low rectal cancer. J Minim Access Surg 2014;10:68-71.

7. Nash GM, Weiser MR, Guillem JG, Temple LK, Shia J, Gonen M, et al. Long-term survival after transanal excision of T1 rectal cancer. Dis Colon Rectum 2009;52:577-82.

8. Kudo S. Endoscopic mucosal resection of flat and depressed types of early colorectal cancer. Endoscopy 1993;25:455-61.

9. Haggitt RC, Glotzbach RE, Soffer EE, Wruble LD. Prognostic factors in colorectal carcinomas arising in adenomas: implications for lesions removed by endoscopic polypectomy. Gastroenterology 1985;89:328-36.

10. Matsuda T, Fukuzawa M, Uraoka T, Nishi M, Yamaguchi Y, Kobayashi $\mathrm{N}$, et al. Risk of lymph node metastasis in patients with pedunculated type early invasive colorectal cancer: a retrospective multicenter study. Cancer Sci 2011;102:1693-7.

11. Yoon YS, Kim J, Hong SM, Lee JL, Kim CW, Park IJ, et al. Clinical implications of mucinous components correlated with microsatellite instability in patients with colorectal cancer. Colorectal Dis 2015;17:O161-7.

12. Peng J, Chen W, Sheng W, Xu Y, Cai G, Huang D, et al. Oncological outcome of $\mathrm{T} 1$ rectal cancer undergoing standard resection and local excision. Colorectal Dis 2011;13:e14-9.

13. Endreseth BH, Myrvold HE, Romundstad P, Hestvik UE, Bjerkeset $\mathrm{T}$, Wibe A, et al. Transanal excision vs. major surgery for T1 rectal cancer. Dis Colon Rectum 2005;48:1380-8.

14. NCCN Clinical Practice Guidelines Oncology: Rectal Cancer V1.2018 [Internet]. Washington (PA): National Comprehensive Cancer Network; c2018 [cited 2018 Jul 21]. Available from: https://www.nccn.org/professionals/physician_gls/pdf/rectal.pdf.

15. Nascimbeni R, Nivatvongs S, Larson DR, Burgart LJ. Long-term survival after local excision for T1 carcinoma of the rectum. Dis Colon Rectum 2004;47:1773-9.

16. Madbouly KM, Remzi FH, Erkek BA, Senagore AJ, Baeslach CM, Khandwala F, et al. Recurrence after transanal excision of $\mathrm{T} 1 \mathrm{rec}-$ tal cancer: should we be concerned? Dis Colon Rectum 2005;48: 711-9.

17. Bentrem DJ, Okabe S, Wong WD, Guillem JG, Weiser MR, Temple LK, et al. T1 adenocarcinoma of the rectum. Trans Meet Am Surg Assoc Am Surg Assoc 2005;123:166-73.

18. Chakravarti A, Compton CC, Shellito PC, Wood WC, Landry J, Machuta SR, et al. Long-term follow-up of patients with rectal cancer managed by local excision with and without adjuvant irra- 
diation. Ann Surg 1999;230:49-54.

19. Paty PB, Nash GM, Baron P, Zakowski M, Minsky BD, Blumberg $\mathrm{D}$, et al. Long-term results of local excision for rectal cancer. Ann Surg 2002;236:522-9.

20. Lee S, Woo CG, Lee HJ, Kim KJ, Ye BD, Byeon JS, et al. Effectiveness of adjuvant radiotherapy after local excision of rectal cancer with deep submucosal invasion: a single-hospital, case-control analysis. Surg Endosc 2015;29:3231-8.

21. Bikhchandani J, Ong GK, Dozois EJ, Mathis KL. Outcomes of salvage surgery for cure in patients with locally recurrent disease af- ter local excision of rectal cancer. Dis Colon Rectum 2015;58:2837.

22. Lee JH, Lee JL, Park IJ, Lim SB, Yu CS, Kim JC. Identification of recurrence-predictive indicators in stage i colorectal cancer. World J Surg 2017;41:1126-33.

23. Bellomo R, Warrillow SJ, Reade MC. Why we should be wary of single-center trials. Crit Care Med 2009;37:3114-9.

24. Sedgwick P. Retrospective cohort studies: advantages and disadvantages. BMJ 2014;348;g1072. 